\title{
Delay of reinforcement: Extended training and multiple shifts
}

\author{
GARVIN MCCAIN, MICHAEL LOBB, WILLIAM ALMAND and DAVID LECK \\ University of Texas at Arlington, Arlington, Texas 76019
}

\begin{abstract}
Several lines of work involving reinforcement manipulations have produced early performance differences between differentially reinforced subjects. Late in training, these differences have disappeared. In the present study, similar effects were found using 10 - and 30 -sec delays of reinforcement. Delay shifts produced an NCE but no PCE. It is proposed that the late acquisition effects have not been considered in most learning models.
\end{abstract}

Over the past few years this laboratory has been involved in several aspects of reinforcement, particularly the effects of long-term training. We have run a series of studies examining the long-term effects of different reward magnitude (McCain, 1970; McCain, Dyleski, \& McElvain, 1971; McCain, Ward, \& Lobb, 1976). Other laboratories (Black, 1969; Campbell, Batsche, \& Batsche, 1972) have also published results relating to these longterm effects. In the case of different magnitude of consistent reward, there are a number of studies in addition to those cited above in which there are early differences, with the large-magnitude groups running faster, later these differences collapse. The story is similar when different magnitudes of partial reward have been used (Capaldi \& Freese, 1974; McCain, 1970; Meyers \& Anderson, 1975). Very recently we have also completed two as yet unpublished studies using different percentages of reward $(25 \% \& 75 \%)$. Again we got an early differences-late collapse.

Extinction results after extended training have also strongly suggested that extinction after medium ranges of training (about 40 trials) and those obtained after extended training are not necessarily the same (Capaldi \& Freese, 1974; McCain, 1970; McCain \& Cooney, 1975; McCain et al., 1971; Meyers \& Anderson, 1975). These extinction results are too complex to be reviewed in a short paper.

Another line of work has involved multiple shifts of consistent reward magnitude. Here the usual negative contrast effect (NCE) was obtained on the initial shift but a positive contrast effect (PCE) was obtained only when the subjects had been shifted from large reward to small reward and then back to large reward (Benefield, Oscós, \& Ehrenfreund, 1974; McCain \& Cooney, 1975).

It should be noted that the studies cited, with the exception of Meyers and Anderson, are all straight-alley studies. Whether the same sort of results can be obtained using other techniques remains to be seen.

The present study, which must be considered as a preliminary effort badly in need of confirmation, represents an attempt to extend our previous work to another dimension of the reinforcement problem.
The classical analyses of delay of reinforcement have emphasized its role in retarding performance. Explanations of this retarded role have involved various concepts such as inhibition, frustration, and interfering responses. This study was not aimed at resolution of any particular theoretical problem. Rather, there were two basically empirical questions: first, does acquisition under different levels of delay resemble that previously found with reward magnitude. Second, given shifts in level of delay, do multiple shifts give results similar to those obtained with successive reward magnitude shifts

\section{METHOD}

\section{Subjects}

The subjects were 30 rats of the Long-Evans strain. All subjects were approximately 90 days old at the beginning of the experiment.

\section{Apparatus}

A plywood alley $160 \mathrm{~cm}$ long was used. Run time was measured over a $45-\mathrm{cm}$ section beginning at the startbox door. Goal time was measured over a $30.5-\mathrm{cm}$ section beginning with the photoelectric cell which terminated the run time and ending with a cell approximately $2 \mathrm{~cm}$ inside the goalbox.

\section{Procedure}

The subjects were put on a deprivation schedule of $13 \mathrm{~g}$ of food per day. This was continued throughout the experiment. On the days when subjects were run in the alley, the daily reward, approximately $2.5 \mathrm{~g}$, was deducted from the cage feeding. Over the first 6 days of deprivation, each object was handled 2 min daily. Beginning on the 7 th day, each subject explored the alley for 3 min daily, all equipment was on during the exploration periods. On the 10th day, subjects were divided into three groups on a random basis. On the 1st day of running, each subject received three running trials and four trials on the 2nd day. The subjects were given seven trials/day throughout the remainder of the study. Throughout the acquisition phase, subjects received 8-45-mg Noyes pellets on each running trial. The groups were: (1) a 30-sec delay control group (30C) which was given a 30-sec goalbox delay, (2) a 10-sec delay control group (10C), (3) an experimental group (E) given 56 acquisition trials with 30 -sec delay then shifted successively to $10 \mathrm{sec}$, $30 \mathrm{sec}$, then $10 \mathrm{sec}$. The first shift consisted of 21 trials. Due to what appeared to be a possible interaction over trials, the second and third shifts consisted of 28 trials each. It would have been desirable to have included other groups such as those in McCain and Cooney (1975). The decision to run only three 


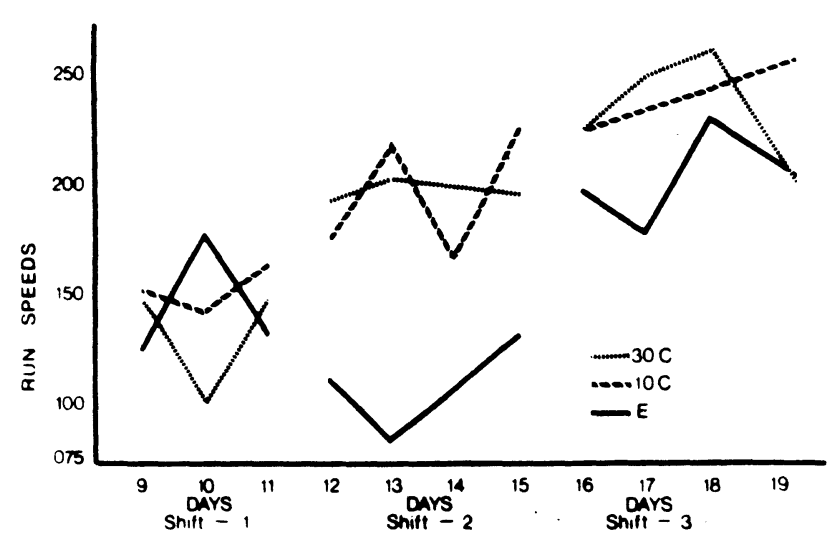

Figure 1. Run speeds for the three shifts.

groups was due to a combination of financial constraints and the need for control groups of a substantial size in order to examine the acquisition process.

Extinction consisted of 21 trials. One-half of the subjects in each group were extinguished with $10-\sec$ goalbox confinement, the other half at 30-sec goal confinement.

Subjects were run in squads of six animals. Each subject was given one running trial in rotation, resulting in an approximate 6-min intertrial interval.

\section{RESULTS}

\section{Acquisition}

All of the results presented are based on transformations $(\log 10[1 / \mathrm{med}+1])$ of the times to run speed (RS) and goal speed (GS). Subjects run on a 10-sec delay schedule ran significantly faster than the $30-\mathrm{sec}$ delay animals over the first 7 days (42 trials) of acquisition $(F=4.88, d f=1 / 28, p<.05)$. This is the usual sort of result reported in the literature. This difference disappears by Day 12 ( 77 trials), and for the remainder of the acquisition phase the difference does not even approach a significant difference. On Days 12-15, Group 10C is slightly faster overall than Group $30 \mathrm{C}$ but the difference is extremely small $(t=.4)$. On Days $16-19$, the means are within a rounding error. As may be seen in Figure 1, all groups changed speeds rather sharply on Day 19. There was reason to suspect that a portion of the subjects were not run on this day. If this day is omitted, Group $30 \mathrm{C}$ is slightly faster than $10 \mathrm{C}$ over Days 16-18. In either case, there are no substantial differences between the control groups during this phase.

\section{Delay Shifts}

As can be seen in Figure 1, there was no PCE during either Shift 1 or Shift 3. In Shift 1, Group E runs slightly faster than Group 10C on Day 10, but this difference does not even approach a significant level $(t<1)$. During Shift 3, Group E is slower than either of the control groups, but the difference was not significant. Shift 2 produced a large and significant NCE in comparisons with either $30 \mathrm{C}$ or $10 \mathrm{C}(\mathrm{p}<.001$ in each case $)$.

\section{Extinction}

The extinction results must be considered in the light of the previous comments regarding Day 19. In the overall analysis, there was no significant main effect except for Days ( $p<.001$ for GS and RS), which only indicates that we were getting an extinction effect. There was a significant Days by Extinction Confinement effect (RS, $F=4.80$, df $=2 / 33, p<.025$; GS, $F=3.71, \mathrm{df}=2 / 88, \mathrm{p}<.05)$. Subjects in the 10 -sec extinction confinement were slower than those in the 30-sec condition on Day 1 (RS, $t=2.50, \mathrm{df}=29$, $\mathrm{p}<.02 ; \mathrm{GS}, \mathrm{t}=1.87, \mathrm{df}=29, \mathrm{p}<.05)$ but faster than the 30-sec group in Day $3(\mathrm{RS}, \mathrm{t}=2.25, \mathrm{df}=29$, $\mathrm{p}<.05 ; \mathrm{GS}, \mathrm{t}=1.87, \mathrm{df}=29, \mathrm{p}<.10>.05)$. The three-way interaction, Days by Acquisition Schedule by Extinction Confinement, was significant in the RS measure $(F=3.03, d f=4 / 48, p<.05)$. If extinction data from the Group $E$ is dropped from the analysis, the RS days and the Days by Extinction Confinement interaction are still significant, as is the three-way interaction $(F=6.75, d f=2 / 32, p<.025)$. Figure 2 shows the four control groups collapsed into two groups consisting of those with goalbox confinement time the same as acquisition delay (A10 E10 \& A30 E30) and those changed (A10 E30 \& A30 E10).

In the analysis, there is a significant days effect, again indicating extinction. The Groups by Days interaction is also significant $(F=6.75, \mathrm{df}=2.36, \mathrm{p}<.005)$. The difference on Day 1 does not reach a significant level $(\mathrm{t}=1.92, \mathrm{df}=19, \mathrm{p}<.10>.05)$. The Day 3 difference is significant $(\mathrm{t}=2.50, \mathrm{df}=19, \mathrm{p}<.02)$.

\section{DISCUSSION}

The most important finding in this study is the early difference-late collapse seen in the case of the control groups. As indicated at the beginning of this paper, a similar phenomenon occurs in consistent reward magnitude, partial reward magnitude, and percentage of partial reward. It now appears that in a number of reinforcement-related conditions, the effects late in training differ from those early in training. These results lead to two points. First, the primary empirical base for most theory has been the early or middle ranges of training. If our conclusions regarding extended training are correct, then this base is

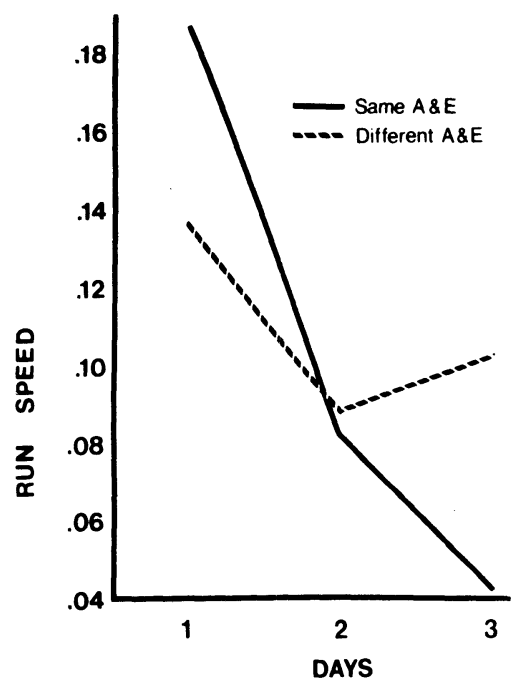

Figure 2. Run speeds for the groups given acquisition and extinction with either the same delay or with different delays. 
not only incomplete but may be misleading. Second, the collapse is related to prior experience with reinforcement-related conditions. It is not clear at this point whether or not preexperimental conditions play a part. In any case, there is some form of adaptation to a specific set of conditions. This latter statement does little more than attach a name and is certainly not considered explanatory. Possibly, as we see more dimensions of this phenomena, a hypothesis will emerge.

The reason for the failure to obtain a PCE on Shift 3, such as has been obtained using consistent reward magnitudes (Benefield et al., 1974; McCain \& Cooney, 1975), is not clear. There are several possibilities. It may be that, although there was a very substantial NCE on Shift 2, delay produces some different effects than does reward magnitude. It is also possible that the differences between the length of delay were not sufficient to get the illusive PCE. Finally, it is also possible that Group E was returning to the baseline as may be seen in Figure 1, and this attenuated the effect. Fred Maxwell (personal communication), using reward magnitudes has found that when subjects were allowed to return to the baseline and then shifted, there was no contrast effect.

In the extinction phase, the emergence of the subjects in the 10 -sec confinement condition as more $R$ to $E$ is hardly surprising. The late showing of greater $R$ to $E$ by the control groups extinguished with a goalbox confinement that was different from their delay in acquisition was unexpected, and the implications are not clear. It is quite possible that the extended training preceeding extinction made discrimination between the acquisition and extinction phases much easier. If this is the case, then discrimination could well be relatively easier for the groups with the same delay and goalbox confinement times as compared to the groups experiencing a new goalbox confinement time.

In brief, while the shift and extinction effects reported here need extensive further investigation, the earlier difference-late collapse phenomenon has now been found in a large number of studies. These studies have been varied in technique and in the type of reinforcement-related conditions. This phenomena seems to be important in formulating or evaluating a wide range of theories.

\section{REFERENCES}

Benefield, R., Oscós, A. \& Ehrenfreund, D. Role of frustration in successive positive contrast. Journal of Comparative and Physiological Psychology, 1974, 86, 648-651.

BLACK, R. W. Incentive motivation and the parameters or reward in instrumental conditioning. In: W. J. Arnold \& D. Levine (Eds.), Nebraska Symposium on Motivation. Lincoln: University of Nebraska Press, 1969.

Campbell, P. E., Batsche, C. J., \& Batsche, G. M. Spaced trials reward magnitude effects in the rat: Single vs. multiple food pellets. Journal of Comparative and Physiological Psychology, 1972, 81, 360-364.

Capaldi, E. J., \& Freese, M. R. Partial reward training level and reward magnitude: Effects on acquisition and extinction. Learning and Motivation, 1974, 5, 299-310.

McCAIN, G. Reward and magnitude and instrumental responses: Consistent and partial reward. Psychonomic Science, 1970, 19. 139-141.

McCain, G., \& Cooney, J. PCE 1: The effects of three reward magnitude shifts. Bulletin of the Psychonomic Society, 1975, 6, 523-526.

McCain, G., Dyleski, J., \& McElvain, G. Reward magnitude and instrumental responses: Consistent reward. Psychonomic Monograph Supplements, 1971, 3, 16(Whole No. 48.)

MCCAIN, G., WARD, R., \& LOBB, M. Reward magnitude and a comment. Bulletin of the Psychonomic Society, 1976, 7, 90-92.

Meyers, L. S., \& Anderson, G. J. Acquisition and extinction following extended partial reinforcement under small or large reward. Bulletin of the Psychonomic Society, 1975, 6, 198-200.

(Received for publication February 26, 1976.) 